\title{
Panarthropod tiptop/teashirt and spalt orthologs and their potential role as "trunk"-selector genes
}

\author{
Brenda I. Medina-Jiménez, Graham E. Budd and Ralf Janssen * (10)
}

\begin{abstract}
Background: In the vinegar fly Drosophila melanogaster, the homeodomain containing transcription factor Teashirt (Tsh) appears to specify trunk identity in concert with the function of the Hox genes. While in Drosophila there is a second gene closely related to tsh, called tiptop (tio), in other arthropods species only one copy exists (called tio/tsh). The expression of tsh and tio/tsh, respectively, is surprisingly similar among arthropods suggesting that its function as trunk selector gene may be conserved. Other research, for example on the beetle Tribolium castaneum, questions even conservation of Tsh function among insects. The zinc-finger transcription factor Spalt (Sal) is involved in the regulation of Drosophila tsh, but this regulatory interaction does not appear to be conserved in Tribolium either. Whether the function and interaction of tsh and sal as potential trunk-specifiers, however, is conserved is still unclear because comparative studies on sal expression (except for Tribolium) are lacking, and functional data are (if at all existing) restricted to Insecta.
\end{abstract}

Results: Here, we provide additional data on arthropod tsh expression, show the first data on onychophoran tio/tsh expression, and provide a comprehensive investigation on sal expression patterns in arthropods and an onychophoran.

Conclusions: Our data support the idea that tio/tsh genes are involved in the development of "trunk" segments by regulating limb development. Our data suggest further that the function of Sal is indeed unlikely to be conserved in trunk vs head development like in Drosophila, but early expression of sal is in line with a potential homeotic function, at least in Arthropoda.

Keywords: Arthropod development, Hox, Homeotic gene, Trunk-selector, Panarthropoda, Onychophora

\section{Introduction}

Segmentation and tagmosis, the subdivision of the anterior-posterior (AP) body axis into serially homologous units (segments) and functional body units (tagmata), represent key innovations in the evolution of arthropods, that have enabled them to become the most successful group of animals [8]. The subdivision of the AP axis allowed evolutionary flexibility that led to the adaptation

*Correspondence: ralf.janssen@geo.uu.se

Department of Earth Sciences, Palaeobiology, Uppsala University,

Villavägen 16, Uppsala, Sweden to almost all ecological niches on the planet, "simply" by altering a segment's morphology without having to disturb the animal's overall body plan.

In the vinegar fly Drosophila melanogaster, the specific identity of each segment is under control of the Hox genes, a group of closely related homeodomain containing transcription factors (e.g. [9, 39, 42]). Ectopic expression of Hox genes and loss of Hox gene function has proven to result in homeotic transformations, the change of a segment from one fate into that of another segment (e.g. [28, 59]). Subsequent work in representatives of other groups of arthropods such as other hexapods, 
crustaceans, myriapods and chelicerates, and even panarthropods (tardigrades and onychophorans), has shown that the overall expression and function of Hox genes is likely conserved (reviewed in $[29,35,56,69]$ ). Body segmentation and formation of tagmata, however, are not entirely under control of the Hox genes. The anterior head region of Drosophila for example is under control of a different gene regulatory network including the socalled head gap genes (e.g. [12, 23, 74]).

Two other genes that are involved in the determination of body regions in Drosophila are the homeodomain encoding gene teashirt (tsh) [18], and the zinc finger encoding gene spalt (sal) [20,38]. Similar to the expression of Hox genes in broad domains along the AP body axis, tsh is expressed in the entire trunk region of the embryo, and mutation of this gene leads to the disruption of the entire trunk region of the embryo [18]. It has further been shown that $t s h$ interacts with trunk Hox genes, and that it represses characteristics of anterior segments in the trunk, making it an essential factor of trunk identity $[3,16,62]$. Similarly, $t s h$ is regulated by gap genes to specify segments [64], and is involved in providing legidentity to trunk appendages [24]. In Drosophila, and its closest relatives, there is a second paralog of this gene, called tiptop (tio) [41] that shares some of the functions of $t s h$ [7]. In all other previously investigated arthropods, however, there is only one ortholog of tio and tsh, called tiptop/teashirt (tio/tsh) (e.g. [45]). Investigation of the tio/ tsh gene expression in other arthropods than Drosophila revealed widely conserved expression suggesting that the overall function of tio/tsh as a trunk-regulator gene may be conserved in arthropods as a whole [24, 45, 55, 68].

The anterior and the posterior borders of tsh-expression in Drosophila are under control of one of the two spalt genes, spalt-major (salm) [38, 40, 60, 62]. Corresponding with the repressive function of salm on tsh, the expression profiles of these genes are complementary in Drosophila with salm being expressed anterior and posterior adjacent to $t s h[40,62]$. In the beetle Tribolium castaneum, however, this correlation is not preserved, suggesting that the single spalt (sal) gene in this species is not regulating tsh expression $[6,68,72]$. Whether the situation in the fly, or the beetle is ancestral, however, has not been investigated.

In this study, we expand investigation of tsh gene expression to Onychophora, and thus Panarthropoda, and provide data on another myriapod model species, the common pill millipede Glomeris marginata. We also, for the first time, investigate early expression patterns of $t s h$ in a spider. Finally, we conducted a comprehensive analysis of spalt ( $\mathrm{sal}$ ) gene expression in several arthropod species and an onychophoran to investigate the potential interaction of sal and tsh genes in Panarthropoda.

\section{Methods}

Animal husbandry and fixation of embryos

Embryos were obtained, embryonic membranes were removed, and embryos were treated for subsequent in situ hybridization experiments, as described in Janssen et al. [30] (Glomeris), Prpic et al. [58] (Parasteatoda tepidariorum), Schinko et al. [65] (Tribolium), and Hogvall et al. [25] (Euperipatoides kanangrensis). Developmental stages were defined as per Janssen et al. [30] (Glomeris), Mittmann and Wolff [47] (Parasteatoda), Strobl and Stelzer [70] (Tribolium), and Janssen and Budd [34] (Euperipatoides).

\section{RNA extraction, gene cloning, whole mount in situ hybridization, and nuclear staining}

Total RNA or messenger RNA was isolated from embryos of mixed stages of Tribolium, Parasteatoda, Glomeris and Euperipatoides, respectively, using TRIZOL (Invitrogen). RNA was reverse transcribed into cDNA using the SuperScript First Strand kit (Invitrogen). Gene fragments were amplified by means of RT-PCR with gene-specific primer-based sequence information from sequenced embryonic transcriptomes of Glomeris and Euperipatoides, and published genomes of Parasteatoda and Tribolium. Nested PCRs were run with internal primers, using $1 \mu \mathrm{l}$ of first PCR-product as template. All used primer sequences are listed in Additional file 5: Table S1. Investigated gene fragments were cloned into the PCRII vector (Invitrogen) and sequenced on an ABI3730XL automatic sequencer (Macrogen, Seoul, South Korea). Gene identifiers are listed in Additional file 6: Table S2. One-colour in situ hybridizations were performed as described in Janssen et al. [37], and two-colour in situ was performed as per Janssen et al. [32] using a digoxigenin(for one gene) and a fluorescein-labelled (for the second gene) probe in parallel. We detected the first gene with the digoxigenin-labelled probe with BM-Purple (Roche) (blue signal). After that, the antibody was removed with $0.1 \mathrm{M}$ glycine, $\mathrm{pH}=2.0$ (10-min incubation at room temperature). We then detected the second probe with SIGMAFAST Fast Red TR/Naphthol AS-Mx (Sigma) (red signal).

Cell nuclei were stained incubating embryos in either $3 \mu \mathrm{g} / \mathrm{ml}$ of $4-6$-diamidino-2-phenylindole (DAPI) or in SYBR Green (Invitrogen) in phosphate buffered saline with $0.1 \%$ Tween-20 (PBST-0.1\%) for $20 \mathrm{~min}$ at room temperature. Excessive DAPI/SYBR Green was removed by several incubation steps in PBST-0.1\%.

\section{Phylogenetic analysis}

We identified potential orthologs by performing reciprocal BLAST searches against the sequenced embryonic transcriptomes of the millipede Glomeris and 
onychophoran Euperipatoides and published genomic sequences of the beetle Tribolium and the spider Parasteatoda. In these BLAST searches, we used the tiptop/ teashirt ortholog of Parasteatoda tepidariorum, and the Drosophila melanogaster spalt ortholog as baits.

Amino acid sequences of the complete coding regions of putative tio/tsh and sal orthologs, and outgroup genes [the Drosophila Zinc finger homeodomain 1 (Zfh1) for tio/tsh, and Krüppel orthologs (for sal)], were aligned using T-Coffee followed by manual editing in SeaView $[22,48]$ using default parameters in MacVector v12.6.0 (MacVector, Inc., Cary, NC). For both genes, Bayesian phylogenetic analyses were executed using MrBayes [26] with a fixed WAG amino acid substitution model with gamma-distributed rate variation across sites (with four rate categories, unconstrained exponential prior probability distribution on branch lengths, and exponential prior for the gamma shape parameters for among-site rate variation. Topologies of the trees were calculated applying 300,000 cycles for the Metropolis-Coupled Markov Chain Monte Carlo (MCMCMC analysis (four chains, chain-heating temperature of 0.2. Markov chains were sampled every 200 cycles. Default settings were used, defining $25 \%$ of the samples as burn-in information. Clade support was calculated with posterior probabilities in MrBayes. Sequence identifiers are listed in Additional file 6: Table S2. Zinc finger motives have been identified manually.

\section{Data documentation}

Bright field microscopy and visualization of DAPI- and SYBR green-stain was executed using a Leica DC490 digital camera equipped with a UV light source mounted onto a MZ-FLIII Leica dissection microscope. When appropriate, linear adjustments were made on colour contrast and brightness using the image-processing software Adobe Photoshop CS6 for Apple Macintosh (Adobe Systems Inc.).

\section{Results}

\section{Sequence analysis}

In all hitherto investigated panarthropods, there is only one tiptop(tio)/teashirt(tsh)-type gene, except for Drosophila that possesses two paralogs, tsh and tio [24, 41, $45,55,68]$. Tio- and Tsh-type proteins can be identified by the presence of a unique set of five zinc fingers (ZFs) (Fig. 1A) [10]. Four of these ZFs are located N-terminally, while the fifth $\mathrm{ZF}$ is located in the $\mathrm{C}$-terminal region of the protein (Fig. 1A). The ZF2, ZF3 and ZF5 are of the $\mathrm{C}_{2} \mathrm{H}_{2}$-type, while $\mathrm{ZF} 4$ is of the $\mathrm{C}_{2} \mathrm{HC}$-type (Fig. 1A). In a phylogenetic analysis, all Tio/Tsh genes cluster together (Additional file 1: Figure S1).
The Drosophila Teashirt protein only possesses three ZFs (ZFs 4 and 5 are missing); Teashirt thus represents a derived paralog. The onychophoran Tio/Tsh protein lacks ZF1, while in the spider this ZF is of the $\mathrm{C}_{2} \mathrm{HC}$-type instead of the $\mathrm{C}_{2} \mathrm{H}_{2}$-type as in all other here investigated arthropods (Fig. 1A).

Spalt (Sal) proteins possess a variable number of ZFs, but all share a unique combination of ZFs [40]: one $\mathrm{N}$-terminal ZF is linked by seven amino acids to a downstream second $\mathrm{ZF}$ that is linked by a unique number of 11 amino acids to a third ZF (Fig. 1B. This combination and linkage of ZFs appears to be unique for Spalt proteins, especially the 11-amino acid link; the seven-amino acid link is more common for ZF proteins (e.g. found in Krüppel proteins) (e.g. [66]). In a phylogenetic analysis, Sal proteins cluster together and separate from Krüppel proteins, the most similar but distantly related zinc finger proteins (Additional file 2: Figure S2).

\section{Embryonic expression patterns of panarthropod tiptop/teashirt (tio/tsh) genes}

Glomeris tio/tsh is expressed in all segments posterior to the postmaxillary segment (Fig. 2A). Expression is enhanced in segmental blocks on either side of the ventral midline, tissue that most probably contributes to the developing ventral nervous system, as well as in the buds of the outgrowing legs (Fig. 2A). Later, expression also occurs in the outgrowing dorsal segmental units and in smaller segmental neurogenic patches in the postmaxillary segment, the maxillary segment and the mandibular segment (Fig. 2B, C). These dots eventually weaken and disappear, but the strong expression in the complete trunk remains (Fig. 2D).

Euperipatoides tio/tsh is expressed in all tissue posterior to the jaw-bearing segment (Fig. 2E-G). Expression of the single tio/tsh gene of the spider Parasteatoda has partially been described by March et al. [45]. However, in their work they only describe late developmental stages, and some aspects of expression at these stages have not been recognized or described. In our analysis, we include early developing stages. Earliest expression is in the form of a patch in the centre of the germ disc (Fig. $2 \mathrm{H}$ ), and a broad ring of expression close to the margin of the disc (Figs. 2H and 3A, B). Careful observation of expression in closely staged embryos reveals that the anterior border of this expression is between the cheliceral and the pedipalpal segment (Figs. 2I, J and 3A-L). Monochromatic double in situ hybridization with tio/tsh and the anterior Hox gene proboscipedia- $A$ ( $p b A)$ [67] shows that there is no expression of tio/tsh anterior to the very strong (dominant) expression of $p b A$ in the pedipalpal segment (Fig. 3I-L). Dichromatic double in situ hybridization, as used for spalt and $p b A$ (see below) did not work for tio/ 


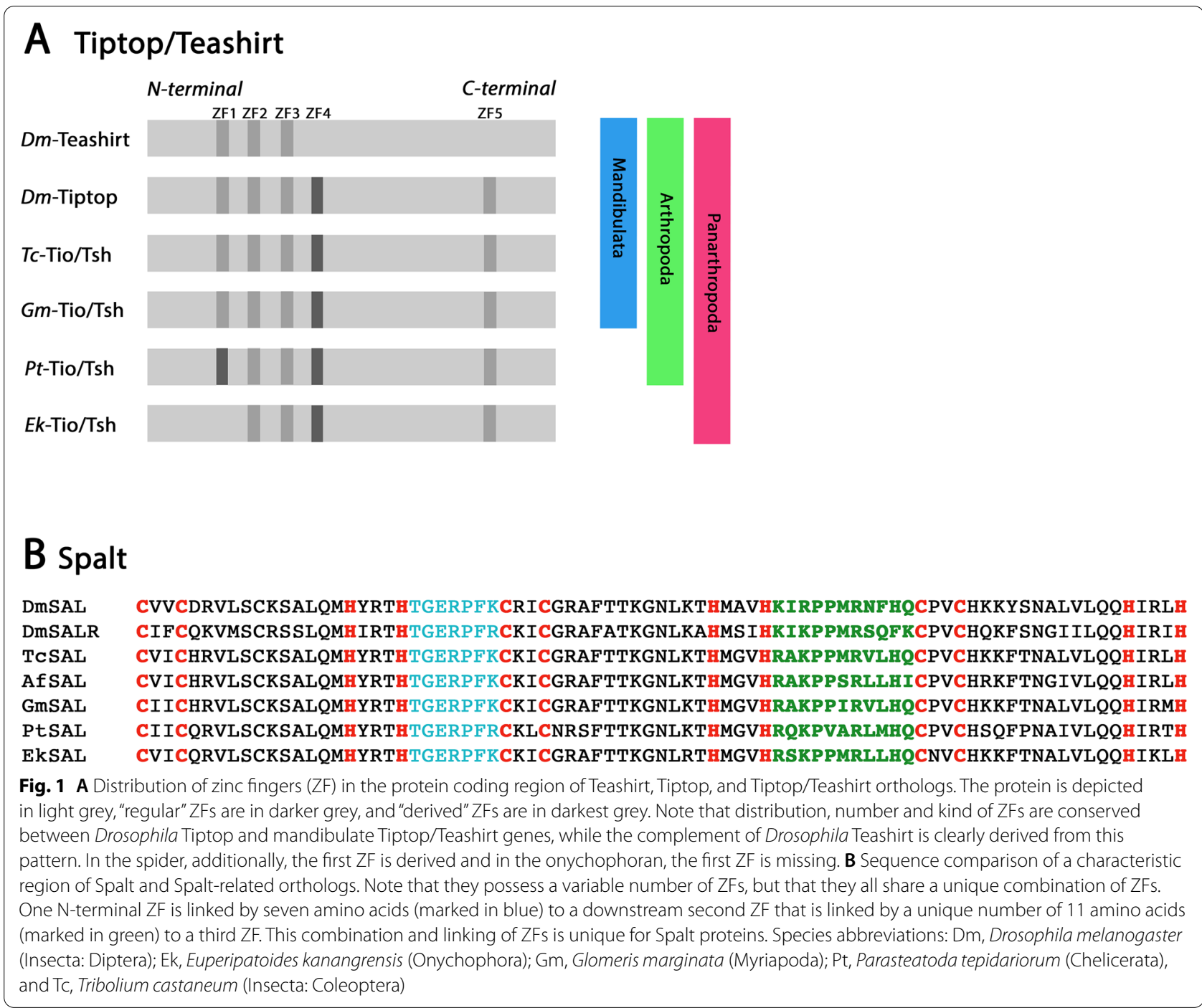

tsh because of its relatively low level of expression. The posterior border of the early gap-gene like domain of tio/tsh is between the first and second walking-leg bearing segment (Fig. 3A-H). The central domain (future posterior of the embryo) is representing expression in the segment addition zone (SAZ) and the newly forming fourth walking-limb bearing segment (Fig. 3D-H). At subsequent developmental stages, expression also appears in the second and third walking-leg bearing segment (Figs. 2I-K and 3G, H). At stages 8.2 and 9.1, expression is in the posterior of the SAZ (or near its posterior margin) (Fig. 2I, J), but at stage 9.2, the posterior of the SAZ is free from expression, suggesting dynamic expression of tio/tsh in the SAZ (Fig. 2K). From stage 9.2 onwards, punctate expression appears in the head lobes and the chelicerae (Fig. 2K-M). In stage 10.1 embryos,

(See figure on next page.)

Fig. 2 Expression of tiptop/teashirt (tio/tsh) in Glomeris (A-D), Euperipatoides (E-G), and Parasteatoda (H-O). In all panels, anterior is to the left except for panels $J$ and $L$ (anterior up). All panels show ventral views, except for $\mathbf{E}-\mathbf{G}, \mathbf{I}-\mathbf{K}$ (lateral views). $\mathbf{E}^{\prime}-\mathbf{G}^{\prime}, \mathbf{I}^{\prime}$, and $\mathbf{M}^{\prime}-\mathbf{O}^{\prime}$ represent DAPI staining of the embryos shown in the corresponding panels. Arrows in $\mathbf{A}-\mathbf{G}$ and $\mathbf{I}-\mathbf{K}$ point to the anterior border of expression. Note that there is no expression anterior to that, except for some staining in the nervous system (filled circles in $\mathbf{B}, \mathbf{C}$, and arrow in $\mathbf{L}$ ). The asterisk in panel $\mathrm{H}$ marks the centre of the germ disc, the future posterior pole of the embryo. Asterisks in $\mathbf{I}, \mathbf{J}$ mark expression in the posterior of the SAZ. ch chelicera, $h /$ head lobe, $j$ jaw, L1 first walking-limb bearing segment, $m d$ mandible, $m x$ maxilla, 01 first opisthosomal segment, $p m x$ postmaxillary segment, $p p$ pedipalp, SAZ segment addition zone, sp slime papilla, T1 first trunk segment 


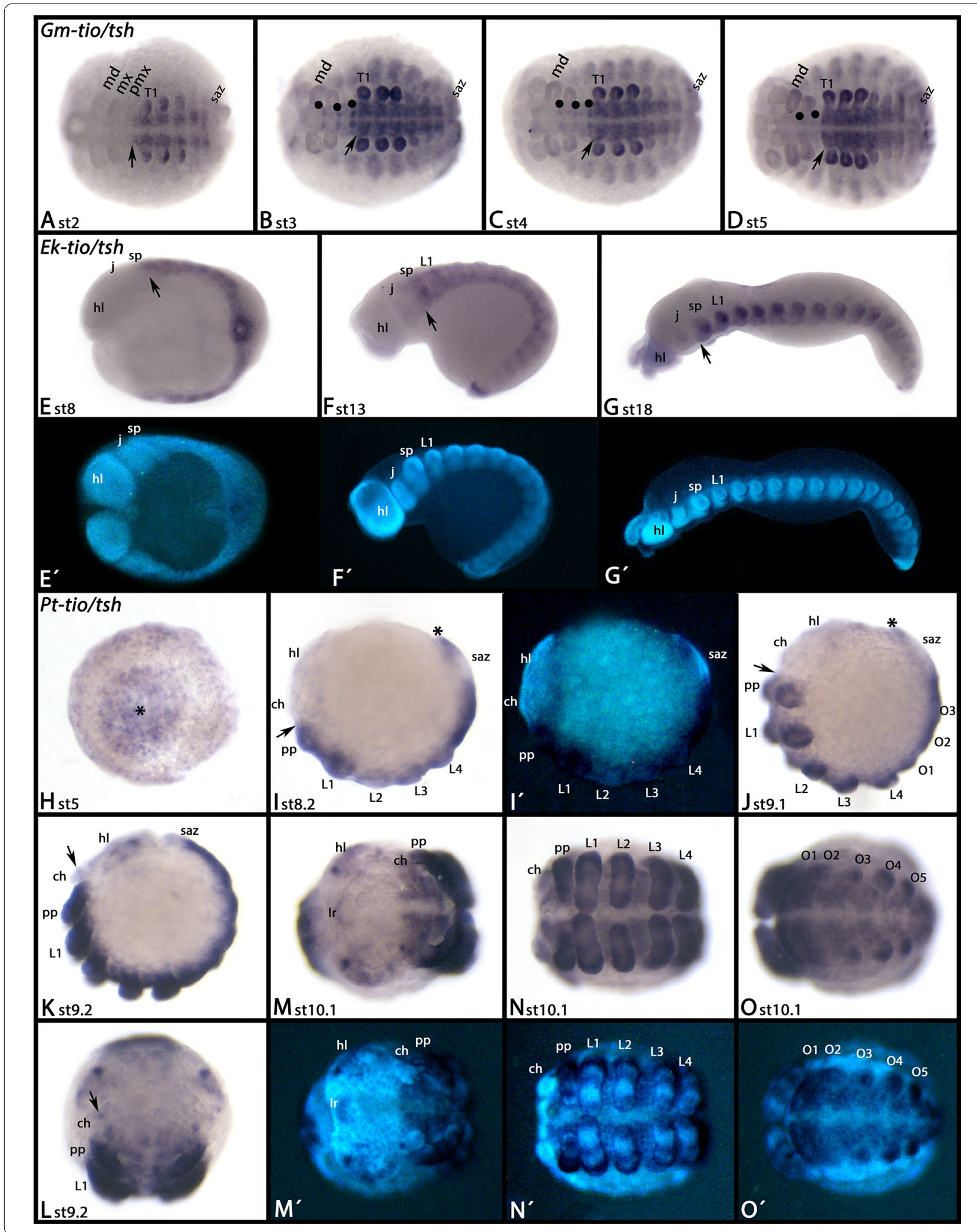


expression in the pedipalps and the legs is in the form of stripes of enhanced expression (Fig. 2N. In the opisthosoma, expression is restricted to ventral tissue including the opisthosomal appendages; the dorsal margins of the opisthosoma do not express tio/tsh (Fig. 2O).

\section{Embryonic expression patterns of panarthropod spalt (sal) genes}

Tribolium sal has been the subject of earlier investigations. However, most of this work focused on either the role of sal in tracheal development or development of the elytra, and thus the focus of these studies was on late developmental stages [15, 72]. Expression of Tribolium sal in a relative early developmental stage was provided by Shippy et al. [68] (in their Additional files 3, 4) and a comprehensive analysis was provided by Berghammer ([6], doctoral thesis in German). Here we investigate the complete embryonic expression profile of sal, including the earliest stages of expression, verifying the expression patterns as described by Berghammer [6]. The gene is first expressed in the form of a broad gap-gene like domain (Fig. 4A-C). Double-staining with the conserved forkhead transcription factor encoding gene sloppy-paired $(s l p)$ [11] and the secondary head gap gene cap-n-collar (cnc) [14] reveals the position of the anterior border of this domain: sal is expressed posterior to the mandibular segment (Fig. 4F-K) (cf. Berghammer [6] who comes to the same conclusion using different genetic markers). From there, expression extends posteriorly throughout the complete germ band, except for the posterior of the SAZ (Fig. 4A-C, F-I). At later developmental stages, however, the gap-gene like expression transforms into a transient metameric pattern similar to that of pair-rule and segment-polarity genes (Fig. 4C, J, K). Towards the end of germ band extension, only the tissue anterior to the SAZ expresses sal in the form of a solid, albeit small, segmentation-gene like domain (Fig. 4D).

Additional expression of Tribolium sal is in the ocular region (Fig. 4B-K), the ventral nervous system (Fig. 4D, $E)$, and an internal structure at the very posterior of the developing embryo (Fig. 4B, C, G, H, J, K). The gap-gene like domain of expression is also present in the dorsal epithelium (Fig. 4K) [5].

Glomeris sal is expressed in the ocular region and in all tissue posterior to the maxillary segment, except for tissue posterior to the SAZ that gives rise to the anal valves (Fig. 5A-C). While expression in the ocular region and the SAZ remains throughout further development, at stage 3, expression in the trunk disappears except for stripes in the dorsal segmental units (Fig. 5D-F).

There are two spalt paralogs in the spider Parasteatoda that display fundamentally different expression patterns suggesting neo-functionalization of these genes after their likely duplication somewhere in the lineage leading to Arachnopulmonata [67].

Parasteatoda sal1 is first expressed in the form of a small domain in the centre of the germ disc (Fig. 6A). This domain then broadens, and an additional ring forms close to the periphery of the disc (Fig. 6B). Then expression disappears from the centre of the former domain resulting in a second ring of expression (Fig. 6C-E). Double-staining with the Hox gene proboscipedia- $A(p b-A)$ [67], and following the stripes throughout development until morphological segmental landmarks form, reveals that the anterior (peripheral) ring corresponds with the pedipalpal segment, and the posterior (central) ring with the third legbearing segment (Fig. 6F-J). Later, this expression disappears, and de novo expression is seen in the ocular region, the tips of all appendages (except for the chelicerae and the labrum), the developing book lungs and tracheal lungs in opisthosomal segments two and three, and in the form of metameric spots along the dorsal of the opisthosoma (Fig. 7A-C).

Expression of Parasteatoda sal2 starts later than that of sal1 and in the form of a solid posterior domain (Fig. 7D). Additional expression is in the tips of the prosomal appendages except for the chelicerae, the labrum, the ocular region (albeit weaker than sal1), and along the dorsal of the opisthosoma (Fig. 7E, F).

Euperipatoides sal is first expressed in all tissue except for the region where the limb buds grow out and the centre of the head lobes (Fig. 8A). Later, sal is expressed along the dorsum of the complete embryo, while there is only faint or no expression in ventral tissue (Fig. 8B). At late developmental stages, expression appears in the tips of the limbs, the most proximal tissue of the limbs, and the limb-mesoderm (Fig. 8C, E), the brain (Fig. 8C, D), and in the form of metameric patches in the ventral tissue of the trunk (Fig. 8C).

(See figure on next page.)

Fig. 3 Early expression of Parasteatoda tiptop/teashirt. A, C, E, G, I and $\mathbf{J}$ represent ventral views and anterior to the left. B, D, F, H, K and $\mathbf{L}$ represent lateral views and anterior up. $\mathbf{A}^{\prime}-\mathbf{L}^{\prime}$ represent SYBR Green staining of the embryos shown in the corresponding $\mathbf{A}-\mathbf{L}$. Arrowheads mark the most anterior expression of tio/tsh. Arrows mark the most posterior extension of the anterior domain of expression. Bars in $\mathbf{I}-\mathbf{L}$ indicate the position of the pedipalp-bearing segment that strongly expresses the anterior Hox gene proboscipedia-A ( $p b A)$. Note that there is no expression of tio/tsh anterior to the expression of $p b A(\mathbf{I}-\mathbf{L})$. Abbreviations as in Fig. 2 


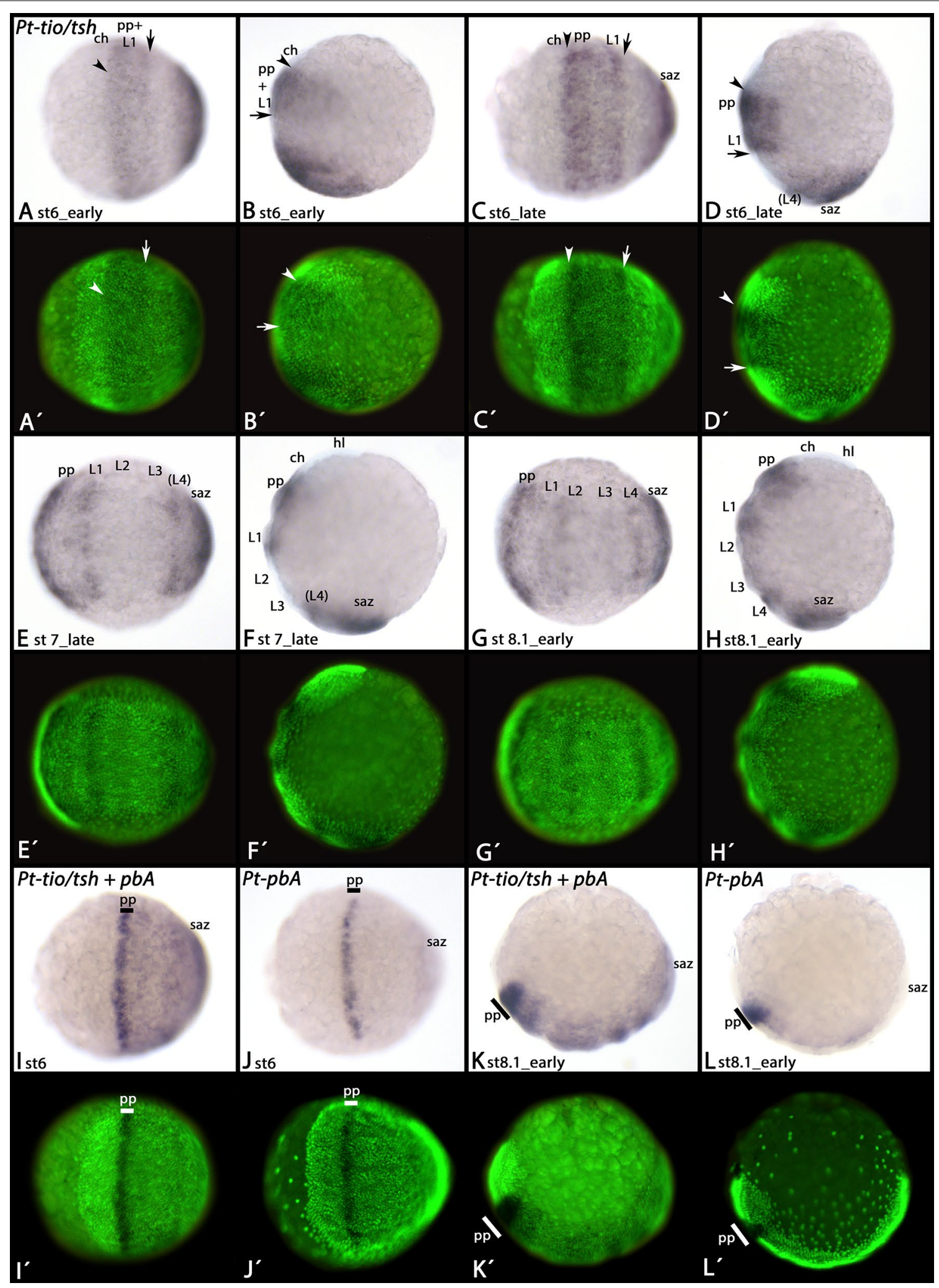




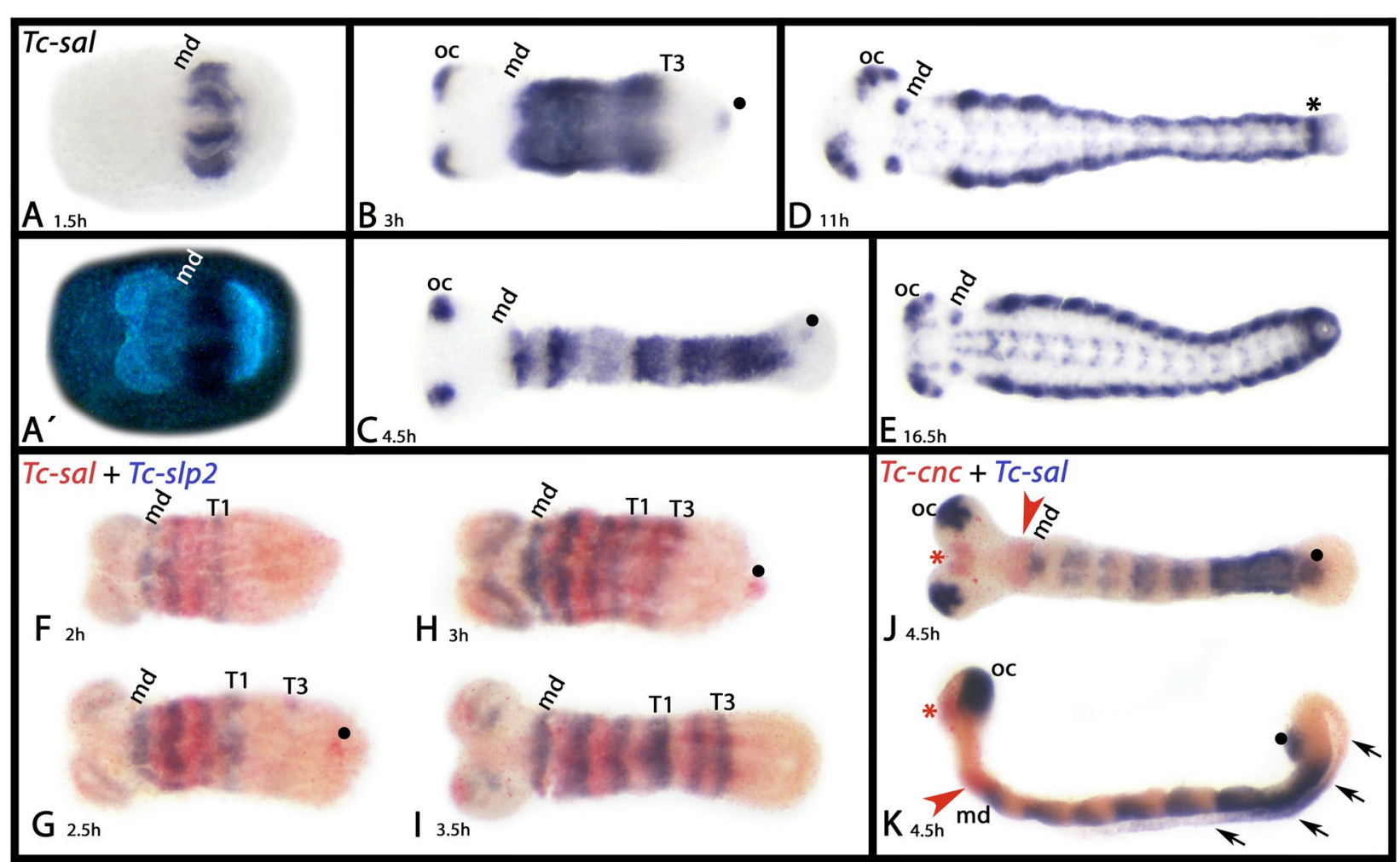

Fig. 4 Expression of Tribolium spalt. In all panels, anterior is to the left, ventral views (except $\mathbf{K}$, lateral view). $\mathbf{A}^{\prime}$ represents a DAPI staining of the embryo shown in $\mathbf{A}$. Filled circles in $\mathbf{B}-\mathbf{D}, \mathbf{H}, \mathbf{J}$ and $\mathbf{K}$ mark expression in an internal structure at the posterior end of the embryo. The black asterisk in $\mathbf{D}$ marks segmentation gene like expression in the last-formed segment. Red asterisks in $\mathbf{J}$ and $\mathbf{K}$ mark the anterior expression domain of cap-n-collar (cnc) (the cap). The red arrowheads mark the posterior domain of $c n c$ (the collar). Arrowhead in $\mathbf{K}$ point to expression in the amnion. Abbreviations as in Fig. 2; oc ocular region, $T$ thoracic segment

\section{Discussion}

\section{Gene expression suggests a function of tiptop/teashirt orthologs as panarthropod "trunk" selector genes}

The term "trunk" is used in a somewhat arbitrary way for arthropods, but usually refers to the body unit that bears the less-modified (often) locomotory appendages, a feature that distinguishes the "trunk" from the "head", another arbitrary body unit that is defined by the presence of highly modified sensory and food-processing appendages (e.g. [4, 17, 27].

A group of genes that is in control of segment-identity and possibly also tagmosis are the famous and highly conserved Hox genes (e.g. reviewed in [29, 35, $56,69]$. It has been suggested that the "head" and the "trunk" tagmata could be under control of different sets of Hox genes, but the shifting expression domains of Hox genes in different groups of arthropods are not strictly aligned with these tagmata (e.g. [29]). However, in Drosophila, it has been shown that the Hox genes interact with $t$ sh that serves as a co-factor of the former. Together, they repress head-identity in the trunk $[2,16,61,62,71]$. One conserved function of tio/tsh genes appears to be the discrimination between highly modified anterior "head" segments, and more posterior (and less modified) "trunk" segments, as recently highlighted by March et al. [45].

We believe however, that the study of March et al. [45] suffers from some technical limitations that may have led the authors to somewhat misinterpret and over-simplify their data. The centipede expression data provided in March et al. [45] are rather unclear, but the statement that tio/tsh is in all limb buds except for the mandibles, is not supported by our millipede data. The statement that expression of tio/tsh in insects is restricted to the thoracic segments is an over-simplification. Clearly, in Tribolium tio/tsh is expressed at comparable level in thoracic and abdominal segments [68]. Unfortunately, expression data of tio/tsh in the milkweed bug Oncopeltus fasciatus are of rather low quality; background staining is hardly distinguishable from specific signal in the segments [24, 45], Additional files 3, 4). Expression in the firebrat Thermobia domestica is not restricted to the thorax either, but extends (albeit at low level) into the abdominal segments (stronger in the first abdominal segment) [55]. 


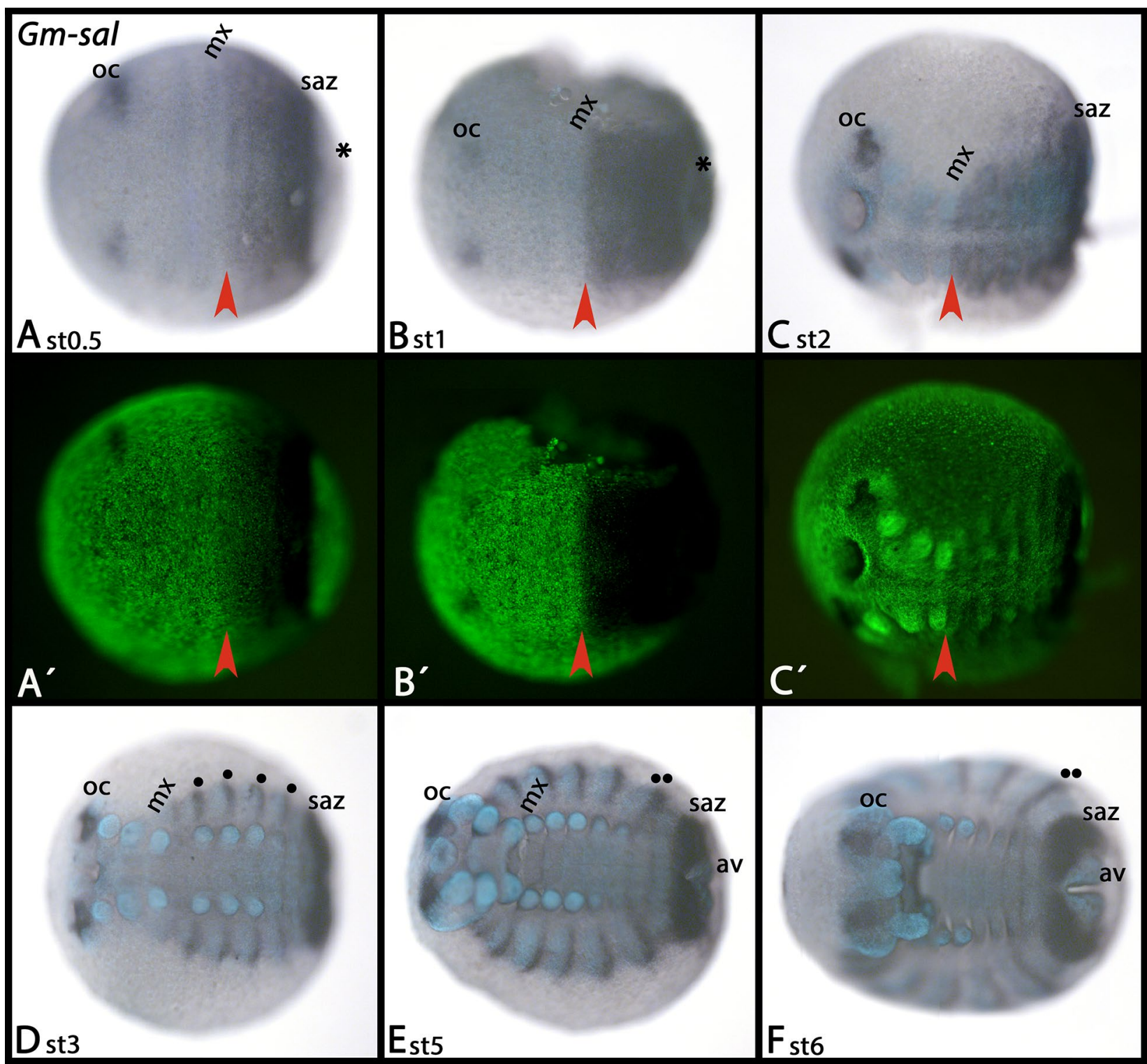

Fig. 5 Expression of Glomeris spalt. In all panels, anterior is to the left, ventral views. A'-C' represent SYBR Green staining of the embryos shown in $\mathbf{A}-\mathbf{C}$. Red arrowheads mark the most anterior border of the broad "trunk" domain of expression; note that expression is also in the ocular region (oc). Filled circles in $\mathbf{D}-\mathbf{F}$ mark expression in the dorsal segmental units; note the double filled-circles in $\mathbf{E}$ and $\mathbf{F}$ that mark two fused domains of expression (cf. [33]). Abbreviations as in Fig. 2

As March et al. [45] pointed out, correlation between Hox genes and tio/tsh genes in the arthropod species they investigated must be different from that in Drosophila [45], and indeed, we could not find any conserved correlation between the expression patterns of Hox genes and tio/tsh in our research organisms either. Correlation between the Hox co-factor disconnected (disco) [43, 64] and tio/tsh [61] does not appear to be conserved in panarthropods outside Drosophila either
[36, 52], this study), suggesting that the entire network of head versus trunk patterning downstream of tio/tsh in these arthropods is significantly different from that in Drosophila.

Data from other bilaterian animals such as mice and flatworms suggest that $t$ sh-like genes may play an ancestral function in head versus trunk development [44, 51], discussed in [45]. However, even the available functional data on insect tio/tsh (the only available functional data in arthropods) are not conclusive 


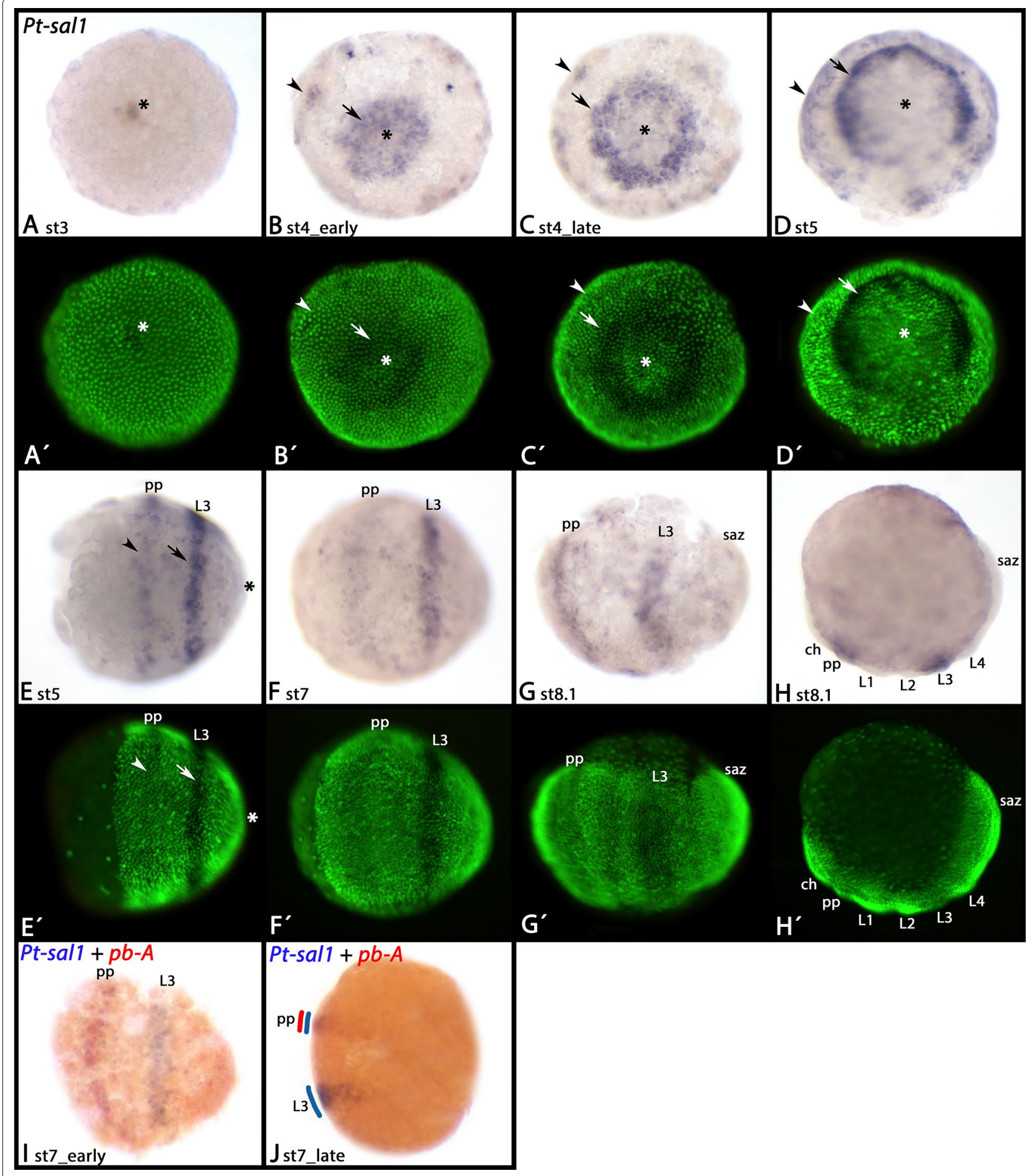

Fig. 6 Early expression of Parasteatoda spalt1. A-D show the germ disc. The asterisks mark the centre of this disc, the later posterior pole of the embryo (cf. E). In all panels, the arrows point to the transforming central domain if expression and the arrowheads point to the more distal (later anterior) domain of expression. $\mathbf{E}-\mathbf{H}$ show the early germ band, ventral views (except for $\mathbf{H}$, lateral view). In $\mathbf{E}-\mathbf{I}$, anterior is to the left. In $\mathbf{J}$, anterior is up, lateral view. $\mathbf{A}^{\prime}-\mathbf{H}^{\prime}$ represent SYBR Green-stained embryos as shown in $\mathbf{A}-\mathbf{H}$. Abbreviations as in Fig. 2 


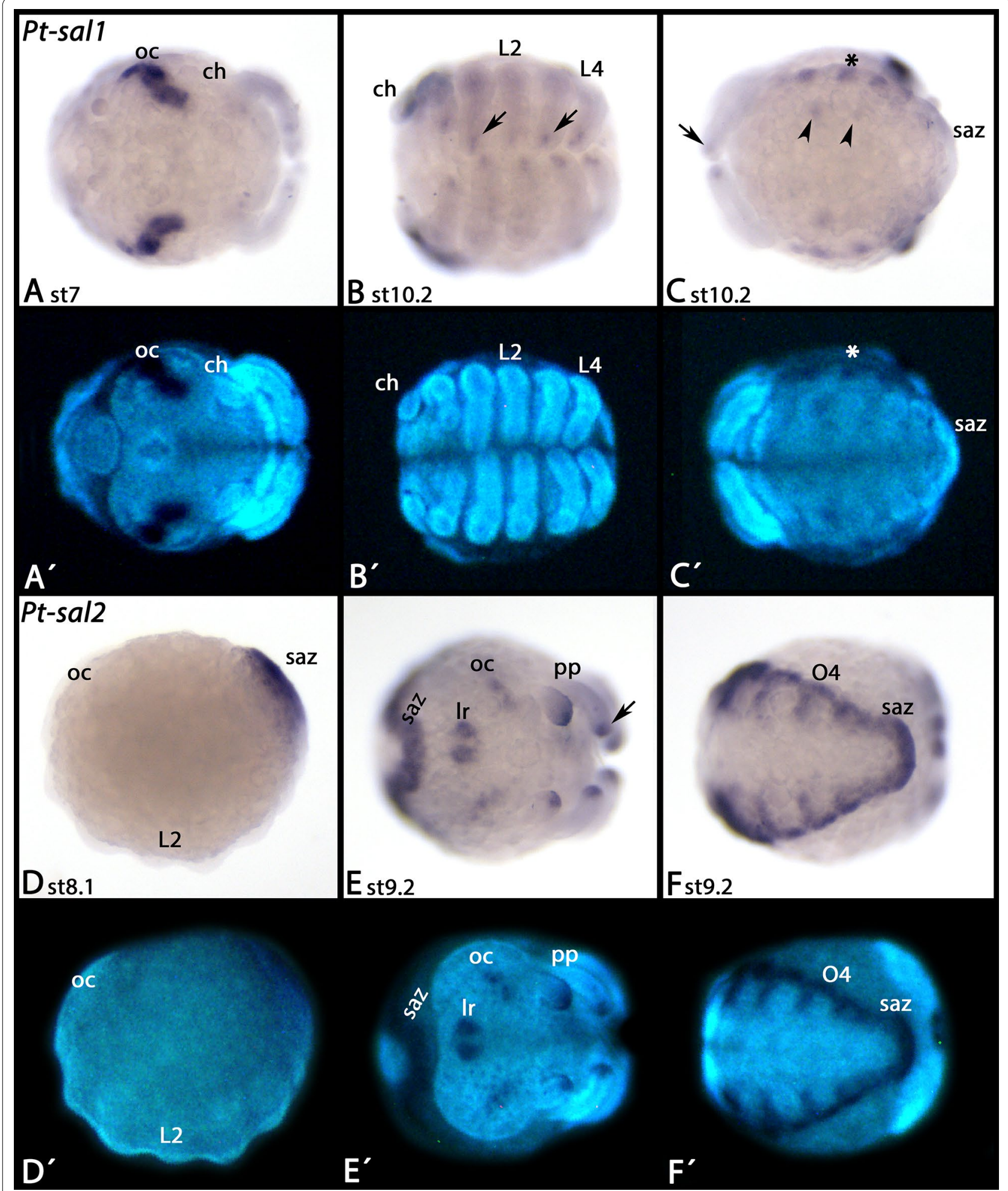

Fig. 7 Late expression of Parasteatoda spalt1 and expression of Parasteatoda spalt2. In all panels, anterior is to the left. Ventral views, except $\mathbf{D}$ (lateral view). $\mathbf{A}^{\prime}-\mathbf{F}^{\prime}$ represent DAPI staining of the embryos shown in $\mathbf{A}-\mathbf{F}$. Arrows in $\mathbf{B}$ and $\mathbf{C}$ point to expression in the tips of the legs. Arrowheads in $\mathbf{C}$ point to expression in the developing book lungs and tracheal lungs. The asterisk marks expression in the dorsal region of the opisthosoma. The arrow in $\mathbf{E}$ points to expression in the tips of the legs. Abbreviations as in Fig. 2; Ir, labrum 


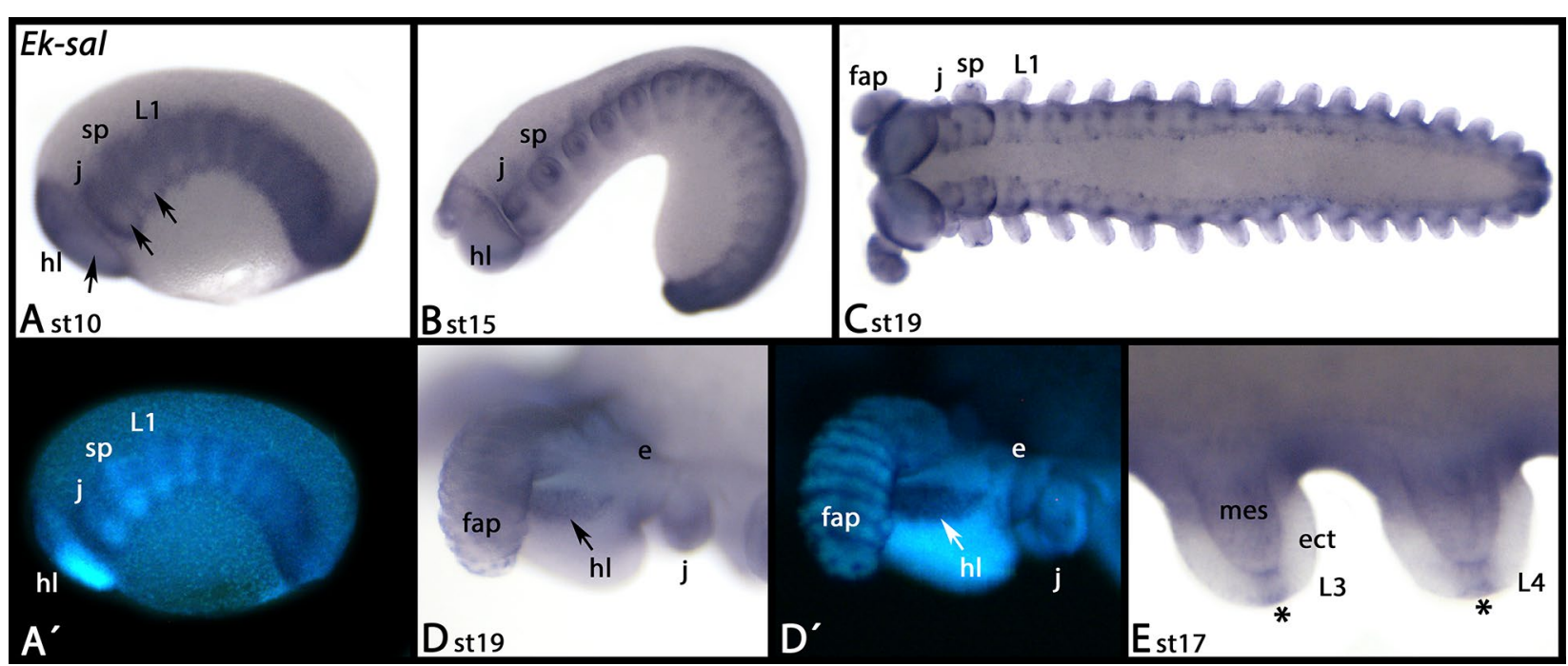

Fig. 8 Expression of Euperipatoides spalt. In all panels, anterior is to the left, lateral views, except $\mathbf{C}^{\prime}$ and $\mathbf{E}$ (ventral views). $\mathbf{A}^{\prime}$ and $\mathbf{D}^{\prime}$ represent DAPI staining of the embryos shown in $\mathbf{A}$ and $\mathbf{D}$. Arrows in $\mathbf{A}$ point to lack of expression in the ventral region. The arrow in $\mathbf{D}$ points to expression in the developing brain. Asterisks in $\mathbf{E}$ mark expression in the tips of the legs. Abbreviations as in Fig. 2; e eye, ect ectoderm, fap frontal appendages (=antennae), mes mesoderm

regarding a conserved homeotic function, which may be because of limited penetrance of RNAi-mediated knock-down of tio/tsh in Oncopeltus and Tribolium (discussed in [45]).

In any case, our gene expression data reveal a clear association of tio/tsh with the development of walkingleg type appendages. In the onychophoran, these are the walking limbs (lobopods) and the slime papillae, that are modified walking limbs that must have evolved after terrestrialization somewhere in the Devonian or Carboniferous period (e.g. [21, 63]). In the slime papillae, the nephridial organs evolved into salivary glands (e.g. [46]). The more derived onychophoran jaws and frontal appendages, however, do not express tio/tsh. In the myriapod, all walking leg-bearing segments and the walking limbs express tio/tsh, but neither of the head appendages (maxillae, mandibles, labrum, antennae) nor (except for secondary ventral expression in the nervous system) their corresponding segments. In the centipede Lithobius atkinsoni, the forcipules (poison fangs) which represent modified walking limbs as well, still express tio/tsh [45]. In the spider, walking legs and pedipalps express tio/tsh, are patterned very similarly, only show little morphological differences (especially in more primitive spiders), and are inter alia used for walking (e.g. [1, $19,53,57,73]$, reviewed in [54]). The situation in spiders however also represents an exception because tio/tsh is expressed in the opisthosomal limb buds that represent highly modified appendages such as the book lungs and the spinnerets (reviewed in [54]). In the opisthosoma of spiders, one (or more) of the posterior Hox genes that are exclusively expressed in this body region may repress the development of walking-leg type appendages, even in the presence of tio/tsh [67].

The available panarthropod expression data clearly suggest a role of tio/tsh in the development of walking-limb type "trunk" appendages. Highly derived "head" appendages, however, do not express tio/tsh, while all walkinglimbs (legs) and walking-limb like appendages such as the pedipalps of spiders, express tio/tsh (summarized in Fig. 9). From an evolutionary point of view, we suggest that the expression domain of tio/tsh must have shifted towards posterior as more anterior segments got specialized and incorporated into the "head". In the last common ancestor of arthropods and onychophorans, likely only the most anterior "frontal appendage-bearing" (i.e. protocerebral) segment did not express tio/tsh, while all other walking-limb bearing segments likely were under the control of tio/tsh (Fig. 9) (e.g. [50]).

\section{Homeotic functions of spalt (sal)}

In the fly Drosophila, expression of the trunk-regulator tsh is at least by part negatively regulated by another homeotic gene, spalt (sal) [20,38], Kühnlein et al. [40], and consequently, in a sal-mutant background the domain of tsh expression expands towards the anterior and towards the posterior [62]. Because of this negative regulation of $t s h$ by sal, in wild type embryos the 


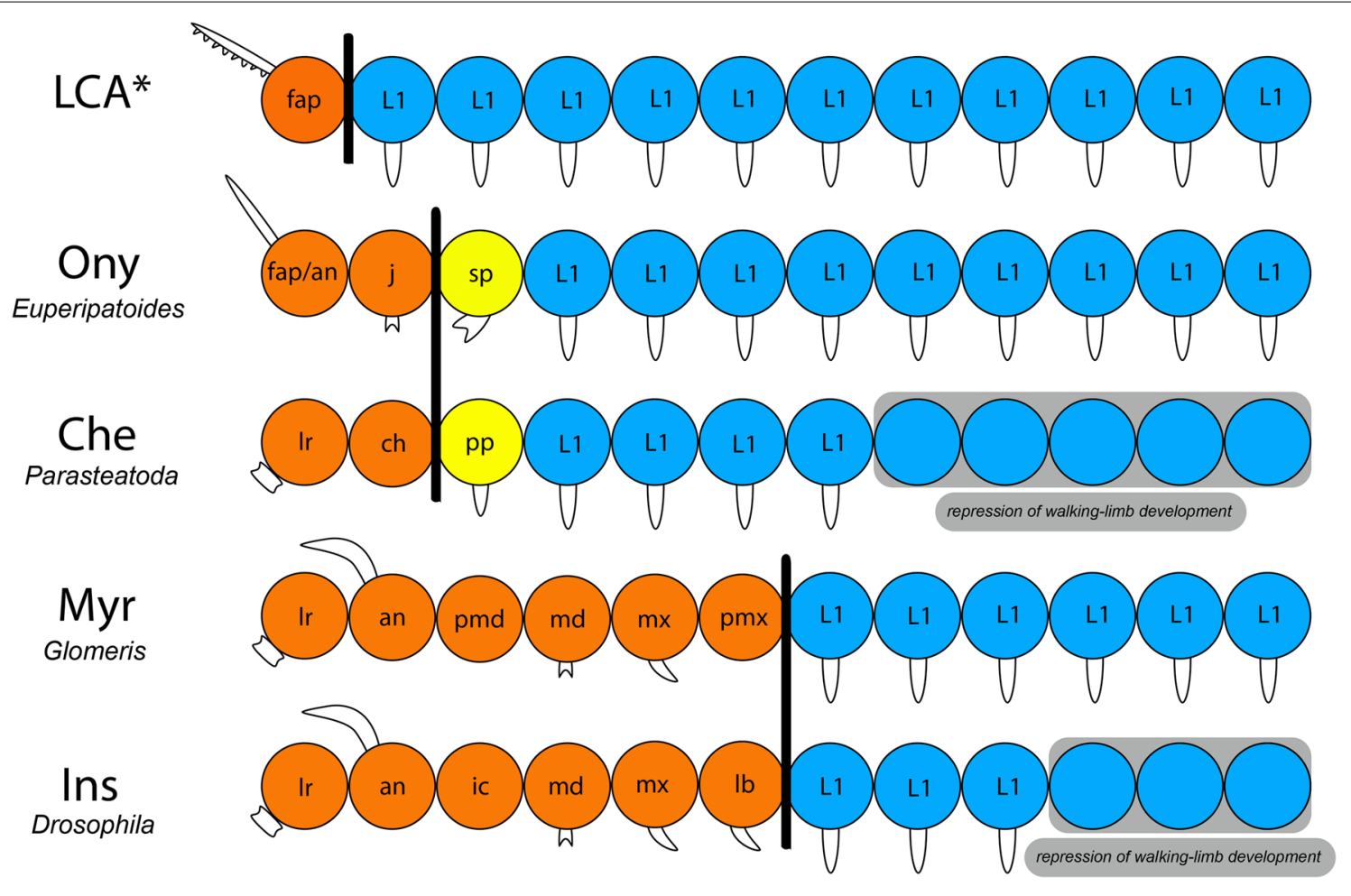

Expression of tio/tsh - unmodified walking-limb in the "trunk"

Expression of tio/tsh - slightly modified limb in the "trunk"

No expression of tio/tsh - heavily modifed limb in the "head"

Expression of tio/tsh - supressed limb development (by other factor(s))

*The LCA is after Smith and Ortega-Hernandez (2014)

Fig. 9 Correlation of tio/tsh expression, appendage-types, and tagmosis in panarthropods and the predicted last common ancestor (LCA) of arthropods and lobopodians. The vertical black lines represent the border between the "head" carrying highly modified appendages (orange), and the "trunk" carrying walking-limb type appendages (blue and yellow). Shown is the situation as predicted for the last common ancestor (LCA), the onychophoran Euperipatoides (Ony), the chelicerate Parasteatoda (Che), the myriapod Glomeris (Myr), and the insect Drosophila (Ins). Abbreviations as in Fig. 2, and fap/an, the onychophoran frontal appendage (a functional antenna), ic intercalary limb-less segment of insects, Ib labium, Ir labrum, pmd premandibular limb-less segment of myriapods

expression of sal is abutting the expression of $t$ sh anteriorly and posteriorly, but the expression domains do not overlap [40,62]. In another insect, the beetle Tribolium, however, such strict repressive function of sal on tsh does not appear to be conserved because the expression domains of both genes significantly overlap $[6,68]$. Nevertheless, RNAi-mediated knock-down of sal in Tribolium caused at least mild homeotic transformations like the development of mandibular features in the maxillae, and the development of a tracheal opening posterior to the eighth abdominal segment [6]. The homeotic function of sal is thus at least partially conserved in the beetle. The exact function and possible interaction partners of $s a l$ are unclear. It is, however, likely that sal interacts with either the Hox genes directly, or via tio/tsh. Knockdown of sal in the brine shrimp Artemia franciscana has shown that sal represses the posterior Hox genes Ultrabithorax (Ubx), abdominalA $(a b d A)$ and AbdominalB $(A b d B)$ [13]. In this crustacean species, sal is expressed in the posterior segment addition zone from which the 
posterior segments are generated, and in the form of transverse segmental stripes that straddle the segmental boundaries [13].

Since the expression pattern of tio/tsh and sal significantly overlap also in Glomeris, Parasteatoda and Euperipatoides, it is unlikely that the interaction of these genes is conserved with respect to the situation in Drosophila. It is however possible that the ancestral role of $s a l$ is the regulation of the posterior Hox genes as demonstrated for Artemia [13]. The expression of sal in Tribolium, Glomeris and Parasteatoda supports this assumption. The early expression of Tribolium and Glomeris sal is strikingly similar to the expression of the posterior Hox genes in these species $[29,31]$ and later this gene is expressed in the SAZ, exactly like in Artemia. Similarly, Parasteatoda sal2 is expressed in the SAZ, and sal1 is early during development expressed in distinct regions along the AP axis, a pattern that is very much in line with a possible regulatory function on the Hox genes (cf. [67]). Expression of Euperipatoides sal, however, is less likely associated with a regulatory function on the Hox genes (cf. [34]). Functional studies will be required to further investigate the potential role of $s a l$ as a conserved regulator of sequence identity in Arthropoda as a whole, a function that is apparently conserved in at least Pancrustacea. At the moment, the best candidate species for such studies is the spider Parasteatoda for which RNAi has been firmly established [49].

\section{Supplementary Information}

The online version contains supplementary material available at https://doi. org/10.1186/s13227-021-00177-y.

\footnotetext{
Additional file 1: Figure S1. Phylogenetic analysis. Tiptop, Teashirt and Tiptop/Teashirt genes form a monophyletic group that is separated from the related Zinc Finger Homeodomain 1 (Zfh 1 ) orthologs of these species. The scale bar represents 0.5 amino acid substitutions per site.

Additional file 2: Figure S2. Phylogenetic analysis of Spalt genes showing that Spalt and Spalt-related genes form a monophyletic group that is separated from the related Krüppel $(\mathrm{Kr})$ orthologs of these species. The scale bar represents 0.5 amino acid substitutions per site.

Additional file 3. Tio/Tsh sequences.

Additional file 4. Sal sequences.

Additional file 5: Table S1. Primers.

Additional file 6: Table S2. Accession Numbers.
}

\section{Acknowledgements}

We are thankful for the support of the New South Wales Government Department of Environment and Climate Change by provision of a permit SL100159 to collect onychophorans at Kanangra-Boyd National Park. We thank Noel Tait, Glenn Brock, David Mathieson, and Robyn Stutchbury for their help during onychophoran collection. cDNAs and embryos of Parasteatoda were provided by the Pechmann group (University of Cologne, Germany), the Prpic group (University of Giessen, Germany), and the McGregor group (Oxford Brookes University, England). Clones, cDNAs and embryos of Tribolium were provided by the Bucher group (University of Göttingen, Germany).

\section{Authors' contributions}

$\mathrm{BIMJ}$ and RJ designed the project and analysed the data. BIMJ performed most of the experiments and documented the data. All authors discussed the results. BIMJ wrote the first draft of the manuscript. RJ and GEB wrote the final version of the manuscript. All authors read and approved the final manuscript.

\section{Funding}

Open access funding provided by Uppsala University. Financial funding was provided by the Swedish Natural Science Council (VR) (Grant No. 621-201504726), and the Marie Skłodowska-Curie Action (MSCA), Innovative Training Network (ITN), H20202-MSCA-ITN-2017 “EvoCELL" (Grant No. 766053).

\section{Availability of data and materials}

All data generated or analysed during this study are included in this published article (and its additional information files).

\section{Declarations}

Ethics approval and consent to participate

Not applicable.

\section{Consent for publication}

Not applicable.

\section{Competing interests}

The authors declare that they have no competing interests.

Received: 2 February 2021 Accepted: 17 May 2021

Published online: 02 June 2021

\section{References}

1. Abzhanov A, Kaufman TC. Homologs of Drosophila appendage genes in the patterning of arthropod limbs. Dev Biol. 2000;227:673-89.

2. Alexandre C, Jacinto A, Ingham PW. Transcriptional activation of hedgehog target genes in Drosophila is mediated directly by the cubitus interruptus protein, a member of the GLI family of zinc finger DNA-binding proteins. Genes Dev. 1996;10:2003-13.

3. Andrew DJ, Horner MA, Petitt MG, Smolik SM, Scott MP. Setting limits on homeotic gene function: restraint of Sex combs reduced activity by teashirt and other homeotic genes. EMBO J. 1994;13:1132-44.

4. Averof M. Evolutionary biology. Origin of the spider's head. Nature. 1998;395:436-7.

5. Benton MA. A revised understanding of Tribolium morphogenesis further reconciles short and long germ development. PLoS Biol. 2018;16:e2005093.

6. Berghammer, Andreas Josef. Keimbahntransformation mit universellem Marker und neue homöotische Gene in Tribolium Castaneum. Dissertation, LMU München: Faculty of Biology; 2004. https://edoc.ub.uni-muenc hen.de/3013/

7. Bessa J, Carmona L, Casares F. Zinc-finger paralogues tsh and tio are functionally equivalent during imaginal development in Drosophila and maintain their expression levels through auto- and cross-negative feedback loops. Dev Dyn. 2009;238:19-28.

8. Budd GE. Why are arthropods segmented? Evol Devc. 2001;3:332-42.

9. Carroll SB. Homeotic genes and the evolution of arthropods and chordates. Nature. 1995;376:479-85.

10. Caubit X, Coré N, Boned A, Kerridge S, Djabali M, Fasano L. Vertebrate orthologues of the Drosophila region-specific patterning gene teashirt. Mech Dev. 2000:91:445-8.

11. Choe CP, Brown SJ. Evolutionary flexibility of pair-rule patterning revealed by functional analysis of secondary pair-rule genes, paired and sloppy-paired in the short-germ insect, Tribolium castaneum. Dev Biol. 2007;302:281-94

12. Cohen SM, Jürgens G. Mediation of Drosophila head development by gap-like segmentation genes. Nature. 1990;346:482-5.

13. Copf T, Rabet N, Averof M. Knockdown of spalt function by RNAi causes de-repression of Hox genes and homeotic transformations in the crustacean Artemia franciscana. Dev Biol. 2006:298:87-94. 
14. Coulcher JF, Telford MJ. Cap'n'collar differentiates the mandible from the maxilla in the beetle Tribolium castaneum. EvoDevo. 2012;3:25.

15. de Miguel C, Linsler F, Casanova J, Franch-Marro X. Genetic basis for the evolution of organ morphogenesis: the case of spalt and cut in the development of insect trachea. Development. 2016;143:3615-22.

16. de Zulueta P, Alexandre E, Jacq B, Kerridge S. Homeotic complex and teashirt genes co-operate to establish trunk segmental identities in Drosophila. Development. 1994;120:2287-96.

17. Dunlop JA, Lamsdell JC. Segmentation and tagmosis in Chelicerata. Arthropod Struct Dev. 2017:46:395-418.

18. Fasano L, Röder L, Coré N, Alexandre E, Vola C, Jacq B, Kerridge S. The teashirt gene is required for the development of Drosophila embryonic trunk segments and encodes a protein with widely spaced zinc finger motifs. Cell. 1991;64:63-79.

19. Foelix RF. Biology of spiders. Oxford: Oxford University Press; 1996.

20. Frei $E$, Schuh $R$, Baumgartner $S$, Burri $M$, Noll $M$, Jürgens $G$, Seifert $E$, Nauber $\mathrm{U}$, Jäckle H. Molecular characterization of spalt, a homeotic gene required for head and tail development in the Drosophila embryo. EMBO J. 1988;7:197-204

21. Garwood RJ, Edgecombe GD, Charbonnier S, Chabard D, Sotty D, Giribet G. Carboniferous Onychophora from Montceau-les-Mines, France, and onychophoran terrestrialization. Invertebr Biol. 2016;135:179-90.

22. Gouy M, Guindon S, Gascuel O. SeaView version 4: a multiplatform graphical user interface for sequence alignment and phylogenetic tree building. Mol Biol Evol. 2010;27:221-4.

23. Grossniklaus U, Cadigan KM, Gehring WJ. Three maternal coordinate systems cooperate in the patterning of the Drosophila head. Development 1994;120:3155-71.

24. Herke SW, Serio NV, Rogers BT. Functional analyses of tiptop and antennapedia in the embryonic development of Oncopeltus fasciatus suggests an evolutionary pathway from ground state to insect legs. Development. 2005;132:27-34

25. Hogvall M, Schönauer A, Budd GE, McGregor AP, Posnien N, Janssen R. Analysis of the Wnt gene repertoire in an onychophoran provides new insights into the evolution of segmentation. EvoDevo. 2014;5:14.

26. Huelsenbeck JP, Ronquist F. MRBAYES: bayesian inference of phylogenetic trees. Bioinformatics. 2001;17:754-5.

27. Hughes NC. Trilobite body patterning and the evolution of arthropod tagmosis. BioEssays. 2003;25:386-95

28. Hughes $\mathrm{CL}$, Kaufman TC. RNAi analysis of Deformed, proboscipedia and Sex combs reduced in the milkweed bug Oncopeltus fasciatus: novel roles for Hox genes in the hemipteran head. Development. 2000;127:3683-94.

29. Hughes $\mathrm{CL}$, Kaufman TC. Hox genes and the evolution of the arthropod body plan. Evol Dev. 2002;4:459-99.

30. Janssen R, Prpic NM, Damen WG. Gene expression suggests decoupled dorsal and ventral segmentation in the millipede Glomeris marginata (Myriapoda: Diplopoda). Dev Biol. 2004;268:89-104.

31. Janssen R, Damen WG. The ten Hox genes of the millipede Glomeris marginata. Dev Genes Evol. 2006;216:451-65.

32. Janssen R, Budd GE, Damen WG, Prpic NM. Evidence for Wg-independent tergite boundary formation in the millipede Glomeris marginata. Dev Genes Evol. 2008;218:361-70.

33. Janssen R. Diplosegmentation in the pill millipede Glomeris marginata is the result of dorsal fusion. Evol Dev. 2011;13:477-87.

34. Janssen R, Budd GE. Deciphering the onychophoran "segmentation gene cascade": gene expression reveals limited involvement of pair rule gene orthologs in segmentation, but a highly conserved segment polarity gene network. Dev Biol. 2013;382:224-34.

35. Janssen R. A molecular view of onychophoran segmentation. Arthropod Struct Dev. 2017:46:341-53.

36. Janssen R. Gene expression reveals evidence for EGFR-dependent proximal-distal limb patterning in a myriapod. Evol Dev. 2017;19:124-35.

37. Janssen R, Andersson E, Betnér E, Bijl S, Fowler W, Höök L, Leyhr J, Mannelqvist A, Panara V, Smith K, Tiemann S. Embryonic expression patterns and phylogenetic analysis of panarthropod sox genes: insight into nervous system development, segmentation and gonadogenesis. BMC Evol Biol. 2018;18:88.

38. Jürgens $\mathrm{G}$. Head and tail development of the Drosophila embryo involves spalt, a novel homeotic gene. EMBO J. 1988;7:189-96.
39. Kaufman T, Seeger M, Olsen G. Molecular organization of the Antennapedia gene complex of Drosophila melanogaster. Adv Genet. 1990:27:309-62.

40. Kühnlein RP, Frommer G, Friedrich M, Gonzalez-Gaitan M, Weber A, Wagner-Bernholz JF, Gehring WJ, Jäckle H, Schuh R. spalt encodes an evolutionarily conserved zinc finger protein of novel structure which provides homeotic gene function in the head and tail region of the Drosophila embryo. EMBO J. 1994;13:168-79.

41. Laugier E, Yang Z, Fasano L, Kerridge S, Vola C. A critical role of teashirt for patterning the ventral epidermis is masked by ectopic expression of tiptop, a paralog of teashirt in Drosophila. Dev Biol. 2005;283:446-58.

42. Lewis E. A gene complex controlling segmentation in Drosophila. Nature. 1978:276:565-70.

43. Mahaffey JW, Griswold CM, Cao QM. The Drosophila genes disconnected and disco-related are redundant with respect to larval head development and accumulation of mRNAs from deformed target genes. Genetics. 2001;157:225-36

44. Manfroid I, Caubit X, Kerridge S, Fasano L. Three putative murine Teashirt orthologues specify trunk structures in Drosophila in the same way as the Drosophila teashirt gene. Development. 2004;131:1065-73.

45. March LE, Smaby RM, Setton EVW, Sharma PP. The evolution of selector gene function: expression dynamics and regulatory interactions of tiptop/ teashirt across Arthropoda. Evol Dev. 2018;20:219-32.

46. Mayer $\mathrm{G}$, Koch M. Ultrastructure and fate of the nephridial anlagen in the antennal segment of Epiperipatus biolleyi (Onychophora, Peripatidae)_evidence for the onychophoran antennae being modified legs. Arthropod Struct Dev. 2005:134:471-80.

47. Mittmann B, Wolff C. Embryonic development and staging of the cobweb spider Parasteatoda tepidariorum C. L. Koch, 1841 (syn.: Achaearanea tepidariorum; Araneomorphae; Theridiidae). Dev Genes Evol. 2012:222:189-216.

48. Notredame C, Higgins DG, Heringa J. T-Coffee: a novel method for fast and accurate multiple sequence alignment. J Mol Biol. 2000;302:205-17.

49. Oda H, Akiyama-Oda Y. The common house spider Parasteatoda tepidariorum. EvoDevo. 2020;11:6.

50. Ou Q, Shu D, Mayer G. Cambrian lobopodians and extant onychophorans provide new insights into early cephalization in Panarthropoda. Nat Commun. 2012:3:1261.

51. Owen JH, Wagner DE, Chen C-C, Petersen CP, Reddien PW. Teashirt is required for head-versus-tail regeneration polarity in planarians. Development. 2015;142:1062-72.

52. Patel M, Farzana L, Robertson LK, Hutchinson J, Grubbs N, Shepherd MN, Mahaffey JW. The appendage role of insect disco genes and possible implications on the evolution of the maggot larval form. Dev Biol. 2007;309:56-69.

53. Pechmann M, Prpic NM. Appendage patterning in the South American bird spider Acanthoscurria geniculata (Araneae: Mygalomorphae). Dev Genes Evol. 2009;219:189-98.

54. Pechmann M, Khadjeh S, Sprenger F, Prpic NM. Patterning mechanisms and morphological diversity of spider appendages and their importance for spider evolution. Arthropod Struct Dev. 2010;39:453-67.

55. Peterson MD, Rogers BT, Popadić A, Kaufman TC. The embryonic expression pattern of labial, posterior homeotic complex genes and the teashirt homologue in an apterygote insect. Dev Genes Evol. 1999;209:77-90.

56. Pick L. Hox genes, evo-devo, and the case of the ftz gene. Chromosoma. 2016;125(3):535-51. https://doi.org/10.1007/s00412-015-0553-6.

57. Prpic NM, Janssen R, Wigand B, Klingler M, Damen WG. Gene expression in spider appendages reveals reversal of exd/hth spatial specificity, altered leg gap gene dynamics, and suggests divergent distal morphogen signaling. Dev Biol. 2003;264:119-40.

58. Prpic NM, Schoppmeier M, Damen WG. Collection and fixation of spider embryos. CSH Protoc. 2008. https://doi.org/10.1101/pdb.prot5067.

59. Pultz MA, Diederich RJ, Cribbs DL, Kaufman TC. The proboscipedia locus of the Antennapedia complex: a molecular and genetic analysis. Genes Dev. 1988;2:901-20

60. Reuter D, Kühnlein RP, Frommer G, Barrio R, Kafatos FC, Jäckle H, Schuh R. Regulation, function and potential origin of the Drosophila gene spalt adjacent, which encodes a secreted protein expressed in the early embryo. Chromosoma. 1996;104:445-54. 
61. Robertson LK, Bowling DB, Mahaffey JP, Imiolczyk B, Mahaffey JW. An interactive network of zinc-finger proteins contributes to regionalization of the Drosophila embryo and establishes the domains of $\mathrm{HOM}-\mathrm{C}$ protein function. Development. 2004;131:2781-9.

62. Röder L, Vola C, Kerridge S. The role of the teashirt gene in trunk segmental identity in Drosophila. Development. 1992;115:1017-33.

63. Rota-Stabelli O, Daley AC, Pisani D. Molecular timetrees reveal a Cambrian colonization of land and a new scenario for ecdysozoan evolution. Curr Biol. 2013;23:392-8.

64. Sanders LR, Patel M, Mahaffey JW. The Drosophila gap gene giant has an anterior segment identity function mediated through disconnected and teashirt. Genetics. 2008;179:441-53.

65. Schinko J, Posnien N, Kittelmann S, Koniszewski N, Bucher G. Single and double whole-mount in situ hybridization in red flour beetle (Tribolium) embryos. Cold Spring Harb Protoc. 2009. https://doi.org/10.1101/pdb. prot5258.

66. Schuh R, Aicher W, Gaul U, Côté S, Preiss A, Maier D, Seifert E, Nauber $U$, Schröder C, Kemler R, et al. A conserved family of nuclear proteins containing structural elements of the finger protein encoded by Krüppel, a Drosophila segmentation gene. Cell. 1986;47:1025-32.

67. Schwager EE, Sharma PP, Clarke T, Leite DJ, Wierschin T, Pechmann M, Akiyama-Oda Y, Esposito L, Bechsgaard J, Bilde T, Buffry AD, Chao H, Dinh H, Doddapaneni H, Dugan S, Eibner C, Extavour CG, Funch P, Garb J, Gonzalez LB, Gonzalez VL, Griffiths-Jones S, Han Y, Hayashi C, Hilbrant M, Hughes DST, Janssen R, Lee SL, Maeso I, Murali SC, Muzny DM, Nunes da Fonseca R, Paese CLB, Qu J, Ronshaugen M, Schomburg C, Schönauer A, Stollewerk A, Torres-Oliva M, Turetzek N, Vanthournout B, Werren JH, Wolff C, Worley KC, Bucher G, Gibbs RA, Coddington J, Oda H, Stanke M, Ayoub
NA, Prpic NM, Flot JF, Posnien N, Richards S, McGregor AP. The house spider genome reveals an ancient whole-genome duplication during arachnid evolution. BMC Biol. 2017;15:62.

68. Shippy TD, Tomoyasu Y, Nie W, Brown SJ, Denell RE. Do teashirt family genes specify trunk identity? Insights from the single tiptop/teashirt homolog of Tribolium castaneum. Dev Genes Evol. 2008;218:141-52.

69. Smith FW, Goldstein B. Segmentation in Tardigrada and diversification of segmental patterns in Panarthropoda. Arthropod Struct Dev. 2017:46:328-40.

70. Strobl F, Stelzer EH. Non-invasive long-term fluorescence live imaging of Tribolium castaneum embryos. Development. 2014;141:2331-8.

71. Taghli-Lamallem O, Gallet A, Leroy F, Malapert P, Vola C, Kerridge S, Fasano $L$. Direct interaction between Teashirt and Sex combs reduced proteins, via Tsh's acidic domain, is essential for specifying the identity of the prothorax in Drosophila. Dev Biol. 2007;307:142-51.

72. Tomoyasu Y, Wheeler SR, Denell RE. Ultrabithorax is required for membranous wing identity in the beetle Tribolium castaneum. Nature. 2005:433:643-7.

73. Turetzek N, Khadjeh S, Schomburg C, Prpic NM. Rapid diversification of homothorax expression patterns after gene duplication in spiders. BMC Evol Biol. 2017;17:168.

74. Wimmer EA, Jäckle H, Pfeifle C, Cohen SM. A Drosophila homologue of human Sp1 is a head-specific segmentation gene. Nature. 1993;366:690-4.

\section{Publisher's Note}

Springer Nature remains neutral with regard to jurisdictional claims in published maps and institutional affiliations.
Ready to submit your research? Choose BMC and benefit from:

- fast, convenient online submission

- thorough peer review by experienced researchers in your field

- rapid publication on acceptance

- support for research data, including large and complex data types

- gold Open Access which fosters wider collaboration and increased citations

- maximum visibility for your research: over $100 \mathrm{M}$ website views per year

At BMC, research is always in progress.

Learn more biomedcentral.com/submissions 